\title{
Cellular phosphoinositides and the maturation of bluetongue virus, a non-enveloped capsid virus
}

Bishnupriya Bhattacharya and Polly Roy

\begin{abstract}
Background: Bluetongue virus (BTV), a member of Orbivirus genus in the Reoviridae family is a double capsid virus enclosing a genome of 10 double-stranded RNA segments. A non-structural protein of BTV, NS3, which is associated with cellular membranes and interacts with outer capsid proteins, has been shown to be involved in virus morphogenesis in infected cells. In addition, studies have also shown that during the later stages of virus infection NS3 behaves similarly to HIV protein Gag, an enveloped viral protein. Since Gag protein is known to interact with membrane lipid phosphatidylinositol $(4,5)$ bisphosphate $\left[\mathrm{PI}(4,5) \mathrm{P}_{2}\right]$ and one of the known binding partners of NS3, cellular protein p11 also interacts with annexin a PI(4,5) $\mathrm{P}_{2}$ interacting protein, this study was designed to understand the role of this negatively charged membrane lipid in BTV assembly and maturation.
\end{abstract}

Methods: Over expression of cellular enzymes that either depleted cells of $\mathrm{PI}(4,5) \mathrm{P}_{2}$ or altered the distribution of $\mathrm{PI}$ $(4,5) \mathrm{P}_{2}$, were used to analyze the effect of the lipid on BTV maturation at different times post-infection. The production of mature virus particles was monitored by plaque assay. Microscopic techniques such as confocal microscopy and electron microscopy (EM) were also undertaken to study localization of virus proteins and virus particles in cells, respectively.

Results: Initially, confocal microscopic analysis demonstrated that PI(4,5) $\mathrm{P}_{2}$ not only co-localized with NS3, but it also co-localized with VP5, one of the outer capsid proteins of BTV. Subsequently, experiments involving depletion of cellular PI(4,5) $\mathrm{P}_{2}$ or its relocation demonstrated an inhibitory effect on normal BTV maturation and it also led to a redistribution of BTV proteins within the cell. The data was supported further by EM visualization showing that modulation of $\mathrm{PI}(4,5) \mathrm{P}_{2}$ in cells indeed resulted in less particle production.

Conclusion: This study to our knowledge, is the first report demonstrating involvement of $\mathrm{PI}(4,5) \mathrm{P}_{2}$ in a nonenveloped virus assembly and release. As BTV does not have lipid envelope, this finding is unique for this group of viruses and it suggests that the maturation of capsid and enveloped viruses may be more closely related than previously thought.

Keywords: BTV, Lipids, PI(4,5) $\mathrm{P}_{2}$, Assembly, Maturation, NS3, Membrane

\section{Background}

Bluetongue virus (BTV), a vector-borne animal pathogen has recently emerged in Europe causing high mortality in sheep. BTV is prototype of Orbivirus genus of the Reoviridae family. Like other family members, BTV is a non-enveloped icosahedral particle and is composed of seven structural proteins (VP1-VP7) organized in two concentric capsids [1]. BTV enters the cells via receptormediated endocytosis and the two outer capsid proteins,

\footnotetext{
* Correspondence: Polly.Roy@lshtm.ac.uk

Faculty of Infectious and Tropical Diseases, London School of Hygiene and Tropical Medicine, Keppel Street, London WC1E 7HT, UK
}

VP2 and VP5 are involved in cell attachment and membrane penetration [2-6]. Although the membrane penetration protein VP5 is non-glycosylated, structurally it resembles the glycosylated fusion proteins of enveloped viruses, such as HIV, herpesviruses, vesicular stomatitis virus and influenza virus [7]. The inner capsid or "core," is comprised of the remaining five proteins, two major (VP7 and VP3), three minor enzymatic (VP1, VP4, VP6) and a genome of ten double-stranded RNA (dsRNA) segments. In addition, BTV also synthesizes four nonstructural proteins (NS1, NS2, NS3/NS3A, NS4) in infected cells, of which the small NS3 protein is

\section{Biomed Central}


glycosylated. Upon infection, the core particles become active, synthesizing ten capped single-stranded RNA transcripts (ssRNAs) which extrude through the capsid pores into the cytoplasm. The newly synthesized core components are recruited by NS2, triggering the formation of virus-specific inclusion bodies (VIBs), the site of the core assembly [8,9]. The addition of newly synthesized VP2 and VP5 onto the cores does not occur within VIBs $[8,10]$. Instead these two proteins appear to be associated with NS3, the only protein of BTV that is glycosylated. NS3 has been localized to intracellular organelles (Golgi complex and Endoplasmic reticulum), cellular membranes and is associated with virus release [11-14]. It also interacts with Tsg101 [13,14], a component of multivesicular bodies (MVBs) and with cellular protein p11 that forms a complex with annexin $2[15,16]$, a member of the cellular exocytotic pathway. Although it has been demonstrated that NS3 localizes to cellular membranes, the cellular components responsible for targeting NS3 to the cellular membrane have not yet been defined. Annexin-2, a binding partner of p11 has been demonstrated to interact with Phosphatidylinositol $(4,5)$ bisphosphate $\left[\mathrm{PI}(4,5) \mathrm{P}_{2}\right]$, a negatively charged lipid molecule in cellular membranes [17-22]. It is known that $\mathrm{PI}(4,5) \mathrm{P}_{2}$ also interacts with members of the SNARE (soluble N-ethylmaleimide sensitive fusion protein receptors) superfamily [23]. Interestingly, while NS3 binds p11, the outer capsid protein VP5 possesses a SNARE domain [24] indicating that BTV NS3 and VP5 may use these cellular components during virus morphogenesis.

The membrane lipid PI $(4,5) \mathrm{P}_{2}$ belongs to a family of lipid molecules that is collectively known as phosphoinositides [25]. These lipid molecules are generally interconverted by specific cellular lipid phosphatases and kinases. While the level of $\mathrm{PI}(4,5) \mathrm{P}_{2}$ in cells is maintained by phosphatases such as polyphosphoinositide 5-phosphatase (5ptaseIV), a cellular kinase, namely phosphatidylinositol-4-phosphate 5-kinase generates the majority of $\mathrm{PI}(4,5) \mathrm{P}_{2}$ in cells. More importantly, this cellular kinase itself is regulated by a number of factors including the small $G$ protein ADP-ribosylation factor 6 (Arf6) [26]. It is known that the expression of a constitutively active form of Arf6, defective for GTP hydrolysis (Arf6/Q67L), alters the localization of cellular PI(4,5) $\mathrm{P}_{2}$ by inducing the formation of $\mathrm{PI}(4,5) \mathrm{P}_{2}$-enriched endosomal structures $[27,28]$. Since annexin-2 and SNARE domains interact with $\mathrm{PI}(4,5) \mathrm{P}_{2}$, and $\mathrm{BTV}$ has been shown to use similar egress machinery to HIV $[13,14]$, this current study was undertaken to investigate whether the membrane lipid $\mathrm{PI}(4,5) \mathrm{P}_{2}$ plays any role in BTV maturation and assembly as it does in HIV.

For this purpose we used a combination of molecular, biochemical and microscopic techniques to investigate the effect of $\mathrm{PI}(4,5) \mathrm{P}_{2}$ on BTV maturation. We found that when the level of $\mathrm{PI}(4,5) \mathrm{P}_{2}$ was reduced by over expression of 5 ptaseIV, the virus titres were also decreased significantly. Furthermore, BTV growth was also affected when $\mathrm{PI}(4,5) \mathrm{P}_{2}$ distribution was altered to form cellular vesicles using a plasmid that expresses an Arf6 mutant (Arf6/Q67L). The results obtained strongly suggest that $\mathrm{PI}(4,5) \mathrm{P}_{2}$ plays a key role in localizing BTV to cellular membranes and promotes efficient virus production. This observation is the first demonstration of the importance of membrane lipids in the morphogenesis of a non-enveloped virus.

\section{Results}

BTV proteins associate with $\mathrm{PI}(4,5) \mathrm{P}_{2}$ in infected cells

We have shown previously that while BTV outer capsid protein VP5 possesses a SNARE domain [24], the nonstructural glycoprotein NS3 has functional similarities with the Gag protein of HIV [13,14]. Since it is known that both HIV Gag and SNARE proteins interact with PI $(4,5) \mathrm{P}_{2},[23]$ we hypothesized that $\mathrm{PI}(4,5) \mathrm{P}_{2}$ might be involved in BTV life cycle. To investigate this, we first examined if VP5 and NS3 in BTV-infected cells are colocalized with $\mathrm{PI}(4,5) \mathrm{P}_{2}$. BTV infected HeLa cells expressing the pleckstrin homology $(\mathrm{PH})$ domain of phospholipase C $\delta 1$ tagged with GFP (PH-GFP) [29] demonstrated co-localization of PH-GFP with NS3 (Figure 1A) $(71.33 \% \pm 1.9)$ and VP5 (Figure 1B) both on the plasma membrane and in the cytoplasmic vesicularlike structures. In contrast, when PH-GFP was expressed alone in uninfected HeLa cells, it was localized primarily on the plasma membrane (Figure 1C). Further, when a specific monoclonal antibody was used to assess localization of these two BTV proteins with membrane PI $(4,5) \mathrm{P}_{2}$ in BTV infected cells, distinct co-localization of NS3 (Figure 1E) and VP5 (Figure 1F) with $\mathrm{PI}(4,5) \mathrm{P}_{2}$ were also clearly visible. As before, uninfected control cells showed $\mathrm{PI}(4,5) \mathrm{P}_{2}$ expression only on the plasma membrane (Figure 1D). These results indicate that $\mathrm{PI}(4,5) \mathrm{P}_{2}$ co-localizes with the viral outer capsid protein VP5 as well as with the glycosylated NS3 in BTV infected cells.

\section{BTV particle production is affected when cellular $\mathrm{PI}(4,5) \mathrm{P}_{2}$} level was perturbed

Since Phosphatases such as 5 ptaseIV have been shown to reduce the cellular level of $\mathrm{PI}(4,5) \mathrm{P}_{2}$ [30], we examined if presence of 5 ptaseIV alters the distribution of PI $(4,5) \mathrm{P}_{2}$ in cells. On transfecting the cells with 5ptaseIV expressing plasmids [31], the distribution of PH-GFP was visibly altered from the plasma membrane (Figure 2A) to a diffuse expression throughout the cytoplasm (Figure 2B). The experiment was repeated three times and in each experiment, a majority of the cells $(\sim 85 \%$ in three different planes) expressing 5ptaseIV showed a diffused expression of PH-GFP suggesting that 5ptaseIV 


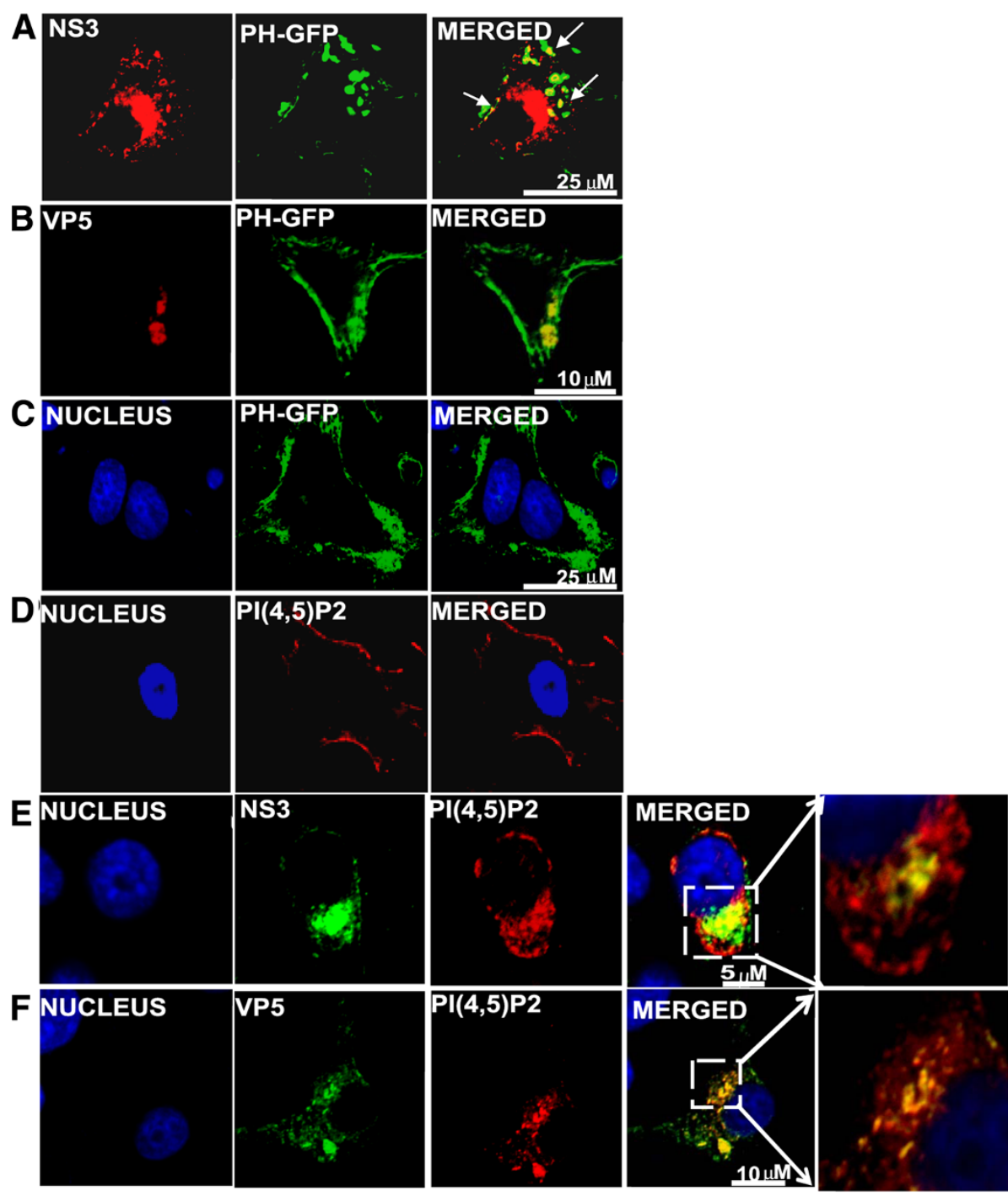

Figure 1 Immunofluorescence analysis of NS3 and VP5 co-localization with PI(4,5) $\mathrm{P}_{2}$ in BTV infected cells. HeLa cells either transfected with plasmid expressing PH-GFP (green)(B-C) or not transfected (E-F), were infected with BTV-1 and analyzed for localization with NS3 (A,E) and VP5 (B,F) 12 hrs post-infection. Control consists of uninfected cells either expressing PH-GFP (C) or cells not expressing PH-GFP, but

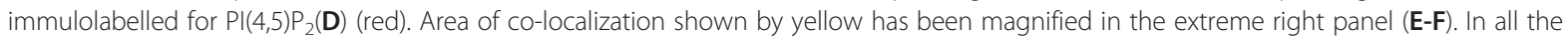
panels the nucleus (blue) was stained by Hoechst. The viral proteins (NS3 and VP5) were stained were either stained with TRITC (red) (A-B) or with FITC (green) (E-F). Small white arrows indicate the areas of co-localization shown by yellow. The scale has been included in the merged panel of each row.

does have an effect on the altered expression of $\operatorname{PI}(4,5)$ $\mathrm{P}_{2}$. In comparison, control cells co-transfected with a mutated version of 5 ptaseIV $(\Delta 1)$ lacking the 5 -phosphatase signature domain ( $\Delta 1$ mutant $)$ showed no effect on the localization of PH-GFP and the pattern was similar to that of panel ' $\mathrm{A}$ ' (compare Figure $2 \mathrm{~A}$ with Figure 2C). To further examine the effect of $\mathrm{PI}(4,5) \mathrm{P}_{2}$ depletion on virus growth and protein production, two different type of mammalian cells (HeLa and BSR) were transfected in parallel with the 5ptaseIV or $\Delta 1$ mutant expression plasmids. HeLa and BSR cells expressing myc-tagged 5 ptaseIV $(>60 \%)$ or $\Delta 1$ mutant $(>60 \%)$ were infected with BTV-1 for 4 or 12 hours (hrs) and VP5, a major outer capsid protein synthesis was examined in both cells (Figure $3 \mathrm{~A}$ ) by western analysis. The results were confirmed by repeating the experiments three times and Western Blot was conducted twice per experiment. In addition, NS2, a major non-structural BTV protein, which is involved in core particle assembly $[8,10,32]$, was used to monitor overall viral replication. Viral protein expressions were observed at $12 \mathrm{hrs}$, but not at 4 hrs post-infection in BTV-1 infected cells expressing either 5ptaseIV (Figure 3A right \& left panels, lane 1 ) or the $\Delta 1$ mutant (Figure $3 \mathrm{~A}$ right \& left panels, 

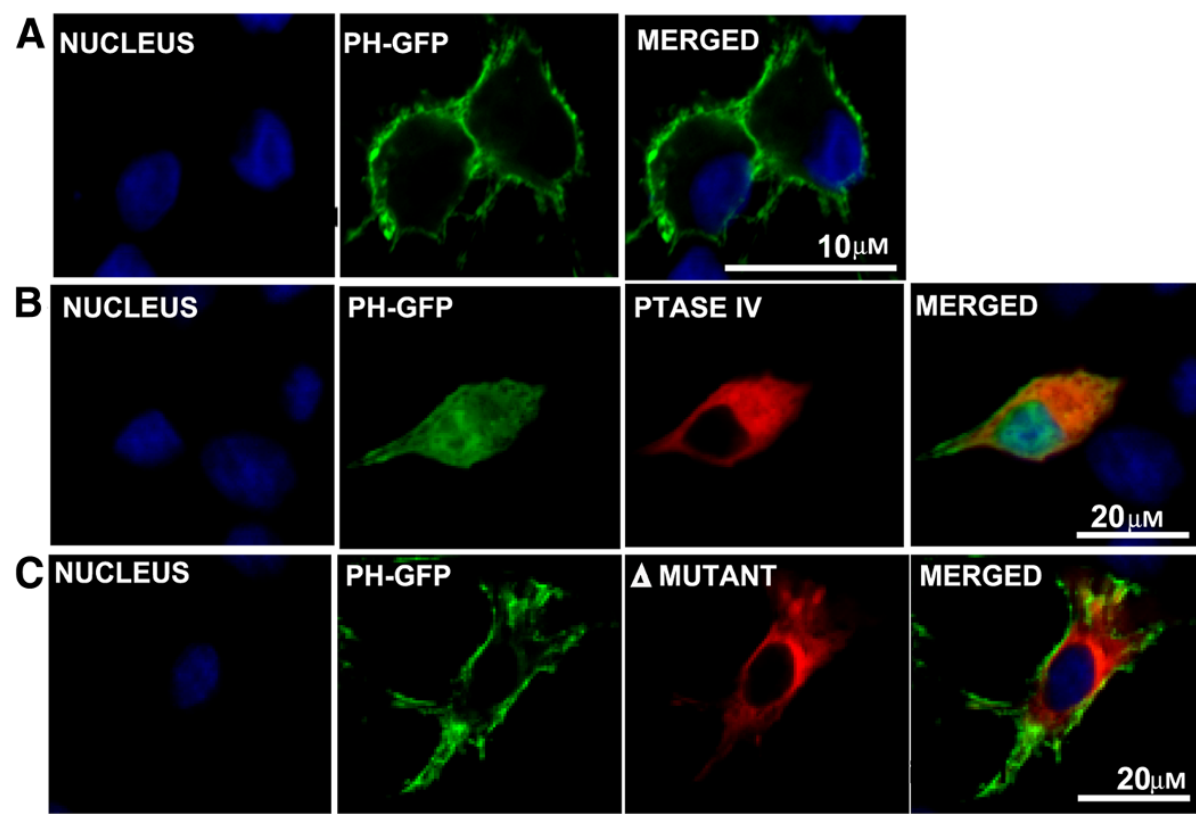

Figure 2 Effect of 5 ptaselV expression on PI(4,5) $\mathbf{P}_{2}$ expression. HeLa cells were transfected with PH-GFP $(\mathbf{A})$ or co-transfected with PH-GFP and myc-tagged 5 ptaselV (red) (B) or the myc-tagged $\Delta 1$ mutant (red) (C). The scale has been included in the merged panel of each row.

lane 2). Infected control cells, not expressing any plasmid, also showed expression of viral proteins at $12 \mathrm{hrs}$ but not at 4 hours post infection (Figure 3A right \& left panels, lane 3). Moreover, expression of cellular proteins (tubulin and actin) was monitored in each experiment: in depleted and infected cells (Figure 3A right \& left panels, lane 1); not depleted and infected cells (Figure 3A right \& left panels, lane 2); control normal cells that have been infected (Figure 3A right \& left panels, lane 3) and uninfected cells (Figure 3A right \& left panels, lane 4). These data confirmed that cellular depletion of $\mathrm{PI}(4,5) \mathrm{P}_{2}$ did not significantly alter the production of cellular proteins. In all experiments the expression of myc-tagged 5 ptaseIV (Figure $3 \mathrm{~A}$ right $\&$ left panels, lane 1 ) and $\Delta 1$ mutant (Figure 3A right \& left panels, lane 2) expression plasmids were also monitored. Further, infected cells treated with transfection reagent also showed similar expression profiles of the proteins as the control infected cells without any transfection (data not shown).

Subsequently, to investigate whether the depletion of $\mathrm{PI}(4,5) \mathrm{P}_{2}$ hinders virus assembly, the total virus titres of the post-transfected cells infected with BTV were determined at 4 and $12 \mathrm{hrs}$. When viral titres at each time point were plotted either as the relative percentages of the titres in infected cells that were not transfected but infected (Figure 3B), or as total titres (Figure 3C), the virus titres in the cells over expressing 5ptaseIV were significantly reduced at $12 \mathrm{hrs}$ post-infection in both HeLa ( $=0.008$ and 0.003 in Figure 3B and 3C right, respectively) and BSR $(p=0.003$ and 0.001 in Figure 3B and $3 \mathrm{C}$ left, respectively) cells. In contrast the reduction in virus titres of infected cells expressing $\Delta 1$ mutant was not significant either when the titres were plotted as a relative percentage (Figure $3 \mathrm{~B}$ ) of infected but not transfected cells $(p=0.07$ in both HeLa and BSR cells) or as total titres $(\mathrm{p}=0.1$ and 0.2 in HeLa and BSR cells, respectively) (Figure $3 \mathrm{C}$ ). Thus, depletion of $\mathrm{PI}(4,5) \mathrm{P}_{2}$ inhibits virus titres but does not interfere with virus protein production in infected cells at $12 \mathrm{hrs}$. In order to negate the deleterious effect of the transfection reagent on virus replication, cells treated with only transfection reagent were also infected with BTV. There was no noticeable difference in virus titres between the cells that were transfected with plasmids or transfection reagent (data not shown) prior to infection.

Since the depletion of $\mathrm{PI}(4,5) \mathrm{P}_{2}$ affected relative virus production, the distribution of viral particles in these cells was visualized by EM (Figure 4). Synthesis of virus particles in the $\mathrm{PI}(4,5) \mathrm{P}_{2}$ depleted HeLa cells by ptase IV expression was decreased significantly $(\sim 86 \%, \mathrm{p}=0.002)$ in comparison to that of the control cells (compare Figure $4 \mathrm{~B}$ with $\mathrm{A}$ ). When the infected and transfected cells were scored in 3 different planes for the presence of virus particles around intra-cytoplasmic vesicles hardly any of the total counted particles bordered these structures. In contrast, control infected cells (Figure 4A) that were not depleted of $\mathrm{PI}(4,5) \mathrm{P}_{2}$ exhibited the presence of virus particles attached to the outer surface of the vesicle-like structures in both type of cells. Thus, the EM data further support the hypothesis that $\mathrm{PI}(4,5) \mathrm{P}_{2}$ 


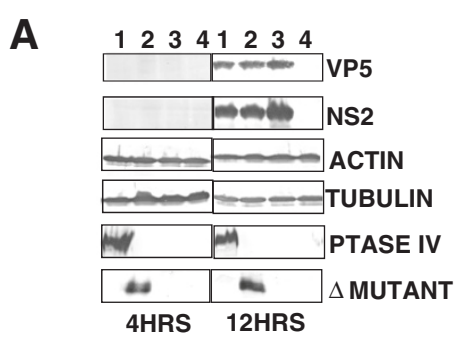

B
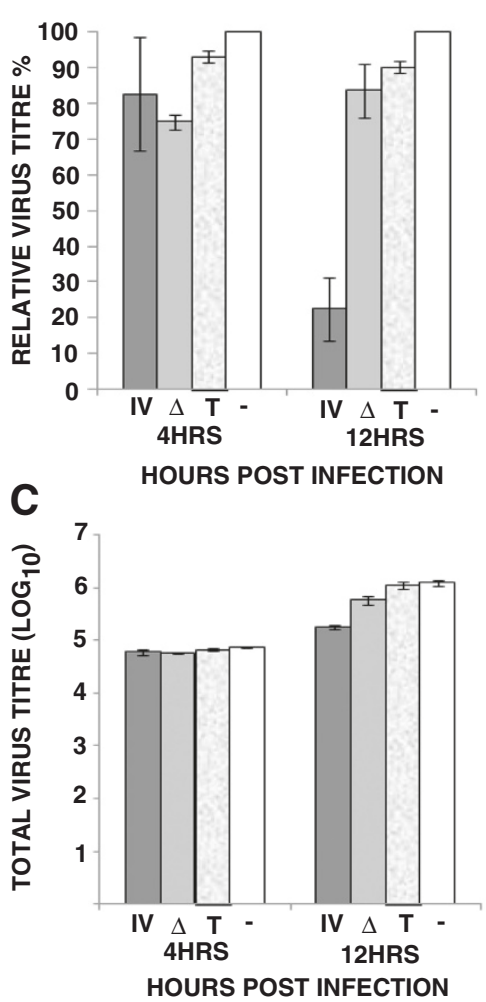
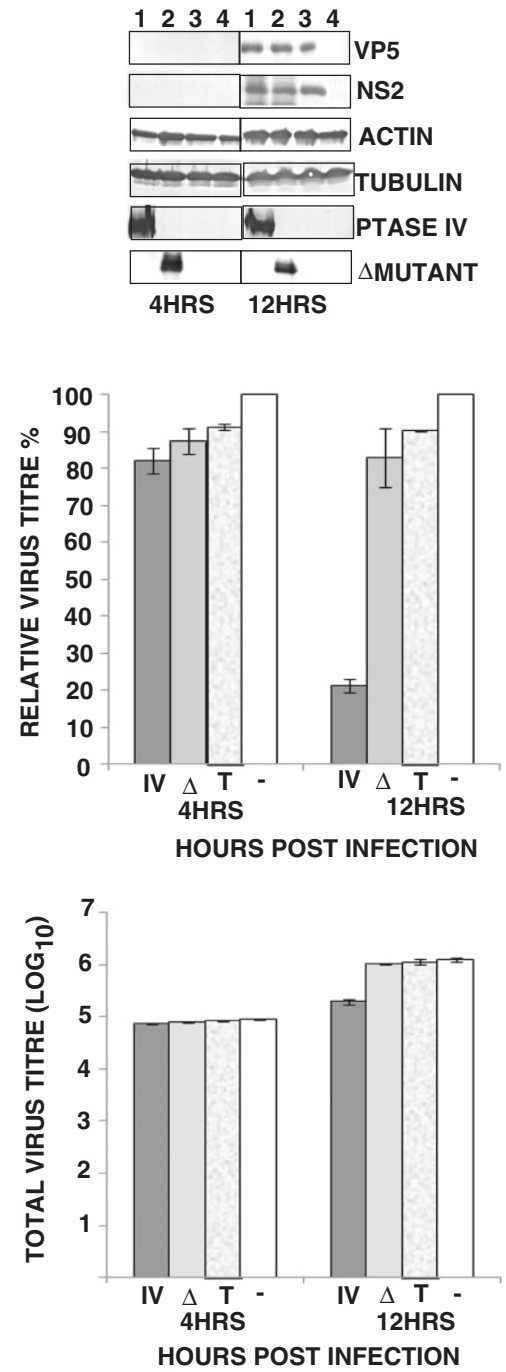

Figure 3 Depletion of PI(4,5) $\mathrm{P}_{2}$ and it's effect on BTV production. (A) Western Blot analysis of HeLa (right) and BSR (left) cells transfected with myc-tagged 5ptaselV (lane 1) or $\Delta 1$ mutant (lane 2) and infected with BTV-1 for the expression of viral (VP5 and NS2) and cellular (actin and tubulin) proteins 4 and 12 hrs post-infection. Controls consist of HeLa cells that have not been transfected but infected with BTV-1 (3) and cells that have neither been transfected nor infected (4). The proteins were detected by specific antibodies. The western blots were repeated 2 times on three independent experiments. (B and $\mathbf{C}$ ) Analysis of relative (B) and total (C) virus titres in infected HeLa (right) and BSR (left) cells in the presence of 5 ptaselV (IV), $\Delta$ mutant $(\Delta)$, transfection reagent only (T) or absence of any plasmid (-). Cells infected with BTV-1, 12 hrs posttransfection with either 5 ptaselV or $\Delta$ mutant were harvested at 4 and $12 \mathrm{hrs} \mathrm{post-infection.} \mathrm{For} \mathrm{the} \mathrm{relative} \mathrm{virus} \mathrm{tires,} \mathrm{the} \mathrm{total} \mathrm{titre} \mathrm{for} \mathrm{each}$ time post-infection was normalized to $100 \%$ for untreated cells. Bars indicate the standard error of three replicates of the experiments.

expression in cells plays an important role in not only BTV particle production but also in the distribution of particles in infected cells.

\section{Changing the normal distribution of $\mathrm{PI}(4,5) \mathrm{P}_{2}$ decreases virus particle production}

Since 5ptaseIV not only dephosphorylates $\mathrm{PI}(4,5) \mathrm{P}_{2}$, but also dephosphorylates $\mathrm{PI}(3,4,5) \mathrm{P}_{3}$ [33], we designed experiments to nullify the effect of $\mathrm{PI}(3,4,5) \mathrm{P}_{3}$ dephosphorylation on BTV replication. For this purpose constitutively active Arf6/Q67L that regulates the activity of phosphatidylinositol-4-phosphate 5-kinase [26,34] and induces the accumulation of $\mathrm{PI}(4,5) \mathrm{P}_{2}$-enriched endosomal structures $[27,28,31]$ was utilized. The effect of PI $(4,5) \mathrm{P}_{2}$ sequestration on BTV replication was first analyzed by co-transfecting HeLa cells with Arf6/Q67L and PH-GFP expression plasmids. Subsequently the cells were infected with BTV-1 and expression of NS3 and VP5 in these cells was monitored by confocal microscopy at 12 hrs post-infection (Figure 5). NS3 expression was not only restricted to the vesicle-like structures formed in the cells expressing Arf6/Q67L, but co-localization was also visualized between PH-GFP, a PI $(4,5)$ $\mathrm{P}_{2}$ marker and NS3 (Figure 5B). In the case of VP5, the 


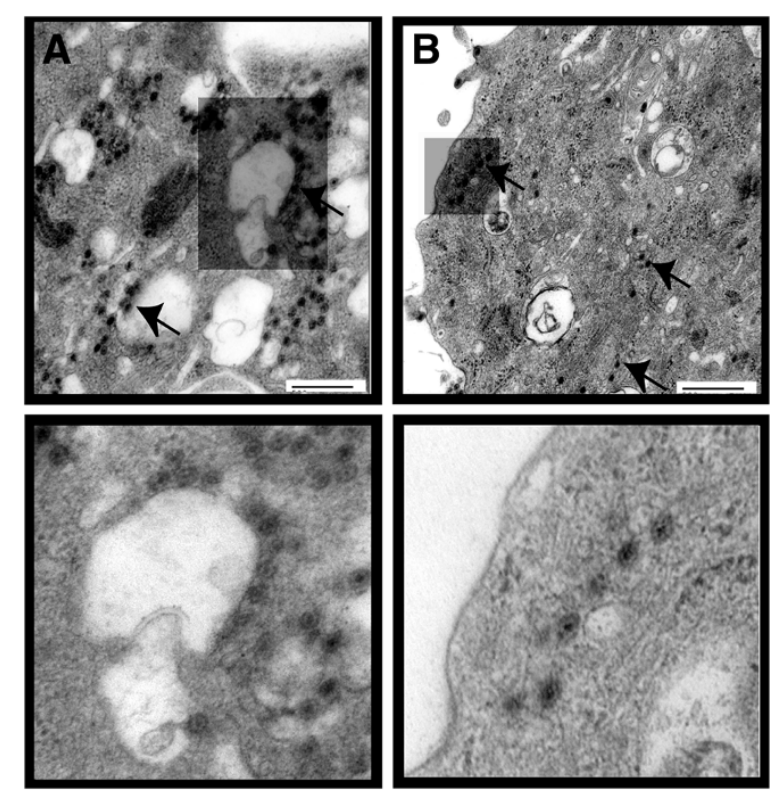

Figure $4 \mathrm{EM}$ analysis of cells depleted of $\mathrm{PI}(\mathbf{4}, 5) \mathrm{P}_{2}$. HeLa (B) cells depleted of $\mathrm{PI}(4,5) \mathrm{P}_{2}$ by transient expression of 5 ptaselV were infected with BTV-1 and analysed for virus particle production. Controls (A) consist of HeLa cells that have not been depleted of PI $(4,5) P_{2}$ but infected with BTV-1. The presence of virus particles in cell section (upper panel) is indicated by arrows. Lower panels are magnified section. The bars represent magnification of $500 \mathrm{~nm}$.

viral protein was visible in the vicinity of the vesiclelike structures formed due to $\mathrm{PI}(4,5) \mathrm{P}_{2}$ sequestration (Figure 5C). Since control transfected (Arf6/Q67L and PH-GFP) cells that were not infected also demonstrated presence of PH-GFP only in intra-cytoplasmic vesicle-like structures (Figure $5 \mathrm{~A}$ ), these results suggested that Arf6/Q67L influenced $\mathrm{PI}(4,5) \mathrm{P}_{2}$ accumulation in intracellular vesicles shifted NS3 localization to these structures.

The effect of Arf6/Q67L on viral protein production and infectious virus titres in HeLa and BSR cells were examined by transfecting with Arf6/Q67L expression plasmid followed by infection with BTV-1. To ensure the expression of the plasmid, confocal microscopy analysis was undertaken which revealed substantial level of Arf6/Q67L expression. When these transfected cells were infected with BTV-1 and viral protein expression were analyzed by WB (repeated 2 times on three independent experiments) at 4 and $12 \mathrm{hrs}$ post-infection, BTV proteins were detected both in HeLa (Figure 6A right) and BSR (Figure 6A left) cells only at $12 \mathrm{hrs}$ but not at $4 \mathrm{hrs}$ post-infection (Figure 6A right \& left, lane 1). Control infected cells that were not expressing Arf6/ Q67L also showed expression of the viral proteins at the same time of post-infection (Figure 6A right \& left, lane 2). Uninfected cells served as negative control
(Figure 6A right \& left, lane 3). Furthermore, production of cellular proteins (tubulin and actin) was monitored in each case including the transfected and infected cells (Figure 6A right \& left lane 1); non transfected but infected cells (Figure 6A right \& left, lane 2) and non transfected and uninfected cells (Figure 6A right \& left, lane 3). All confirmed that sequestration of $\mathrm{PI}(4,5) \mathrm{P}_{2}$ did not alter the production of cellular proteins. In all these experiments the expression of HA tagged Arf6/Q67L expression plasmid was also monitored (Figure 6A right \& left, lane 1). In addition, infected cells transfected with an unrelated plasmid or treated with transfection reagent showed similar expression profiles of the proteins as the control infected cells without any transfection (data not shown).

The effect of Arf6/Q67L on virus yield was further investigated by infecting the Arf6/Q67L expressing cells and analyzing the total titres by plaque assay as described in Materials and Methods (Figure 6B and C). When the relative titres were compared to control cells (Figure 6B, HeLa, right, and BSR, left) that were infected but not transfected, cells expressing the dominant negative plasmid, Arf6/Q67L showed significant reduction in viral tires at $12 \mathrm{hrs}(\mathrm{p}<0.0001$ in HeLa and $\mathrm{p}=0.0007$ in BSR) post-infection, but not at 4 hrs ( $p=0.01$ in HeLa and $\mathrm{p}=0.2$ in BSR). A similar trend was also observed for total viral tires (Figure 6C) where the reduction at 12 hrs was more significant $(p=0.003$ and 0.001 for HeLa and BSR cells, respectively) than $4 \mathrm{hrs}(\mathrm{p}>0.005$ for HeLa and BSR) post infection in the both cell types. Since, no viral proteins were expressed at $4 \mathrm{hrs}$ postinfection, this suggested that the viral particles counted at this early time post infection were the input virus particles and not newly assembled ones. Although the percentage of decrease in relative virus titre was more in HeLa cells $(90 \%)$ than BSR (70\%), similar trends in decrease of relative virus titre confirmed that perturbation of cellular $\mathrm{PI}(4,5) \mathrm{P}_{2}$ inhibits virus production. Thus, the formation of $\mathrm{PI}(4,5) \mathrm{P}_{2}$ enriched vesicles inhibits virus production but does not interfere with virus protein production.

Since sequestration of $\mathrm{PI}(4,5) \mathrm{P}_{2}$ into intra-cytoplasmic vesicles by Arf6/Q67L expression hampered the relative virus production, it was important to determine whether disrupting the distribution of $\mathrm{PI}(4,5) \mathrm{P}_{2}$ in cells impairs virus particle distribution. When the transfected and infected cells were compared by EM from three different planes of the cells' sections (Figure 7), the total number of virus particles was significantly less than the nontransfected cells (about 90\% less, $\mathrm{p}=0.008$ ) (see Figure $7 \mathrm{~A}$ and $7 \mathrm{~B}$ ). In addition a large number of large vesicles were visible (see Figure 7A). Thus, the EM data further support the hypothesis that $\mathrm{PI}(4,5) \mathrm{P}_{2}$ expression in cells plays an important role in BTV particle production. 


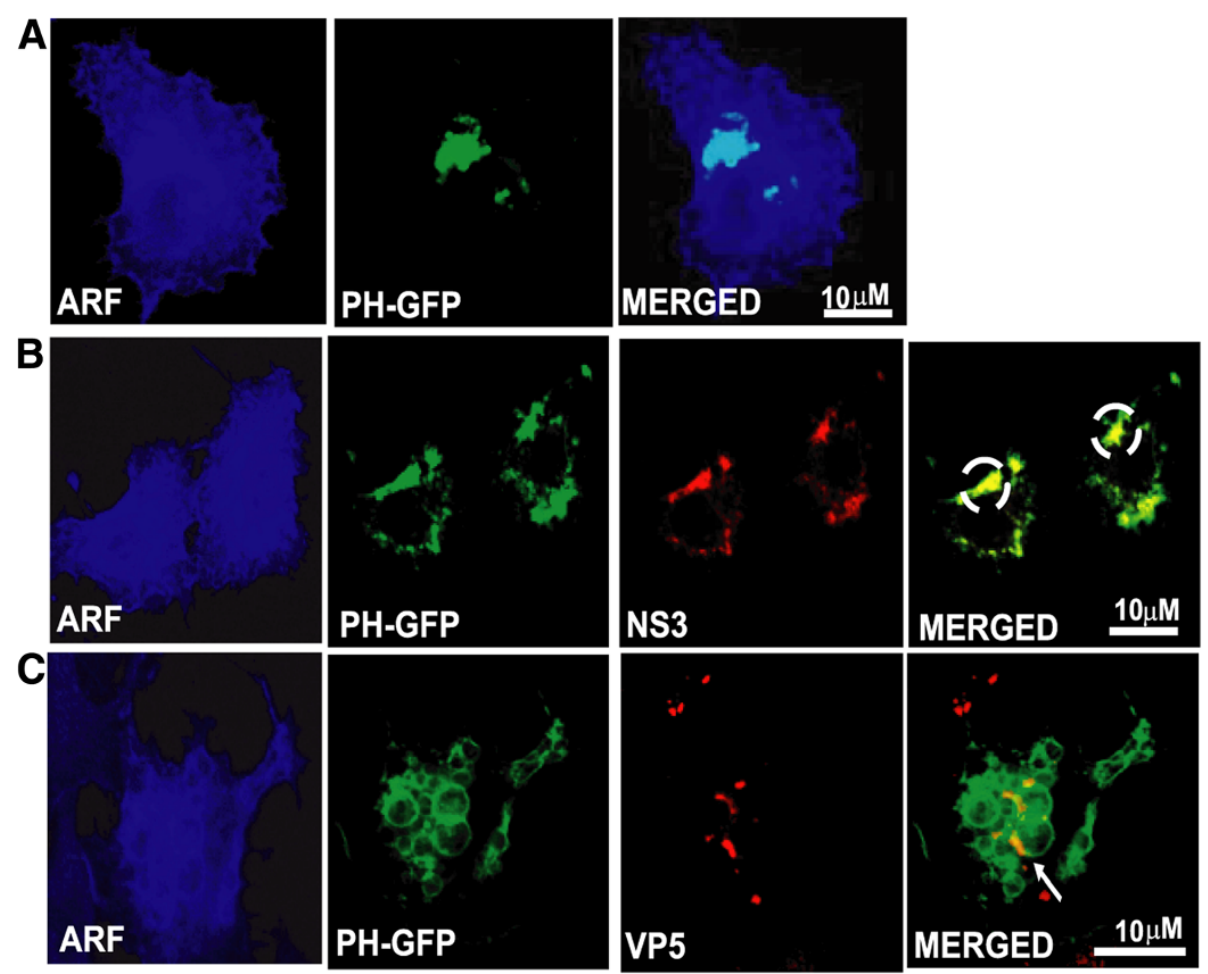

Figure 5 Sequestration of virus proteins in Arf6/Q67L induced $\mathrm{PI}(4,5) \mathrm{P}_{2}$-enriched vesicles. Immunofluorescence microscopy of HeLa cells expressing HA-tagged Arf6/Q67L and PH-GFP followed by BTV-1 infection. The infected cells were analyzed 12hrs post-infection for localization of NS3 (B) and VP5 (C). Control consists of cells that have been co-transfected with PH-GFP and HA-tagged Arf6/Q67L, but not infected (A). While PH-GFP localization is shown in green, HA-tagged Arf6/Q67L was detected with Alexa Fluor (blue) and all the viral proteins with TRITC (red). White circles point to co-localized patches. The scale has been included in the merged panel of each row.

\section{Discussion}

Although BTV is a non-enveloped virus, the outer capsid protein VP5 possesses fusogenic property [5] as well as structural similarity with the fusion proteins of enveloped viruses [7]. In addition, VP5 also possesses a SNARE domain [24] that is very similar to SNARE domains of cellular proteins that have been shown to interact with $\mathrm{PI}(4,5) \mathrm{P}_{2}[35,36]$. In addition a second BTV protein, NS3 has some functional similarities with HIV Gag $[13,14,16]$ and it also interacts with cellular annexin2 [15], which in turn, interacts with $\mathrm{PI}(4,5) \mathrm{P}_{2}$ present in membranes [17-22]. These compelling findings pointed at $\mathrm{PI}(4,5) \mathrm{P}_{2}$ as the common denominator in the interactions between a non-enveloped virus (BTV) and host cells. In the case of enveloped viruses such as HIV, where the virus assembly occurs on the cellular membranes [37-40], the basic domain of HIV matrix protein (MA) has been suggested to contribute to the membrane binding of Gag by interacting with acidic phospholipids on the cytoplasmic leaflet of membranes $[31,41,42]$. Furthermore, a recent report has also shown that the subcellular localization of Gag in MLV infected cells is also determined by $\mathrm{PI}(4,5) \mathrm{P}_{2}[43]$.
This study therefore focused on the effect of $\mathrm{PI}(4,5) \mathrm{P}_{2}$ during virus maturation. On the basis of earlier studies that have successively used PH-GFP as a marker for PI $(4,5) \mathrm{P}_{2}$ in cells [43], the same lipid marker was also utilized to study the role of the negatively charged lipid in BTV maturation. The experiments undertaken on particle production and protein synthesis were limited up to 12 hrs post-infection as the first replication cycle of BTV infection is completed by 16 hrs post-infection. Additionally, in order to negate whether the effects of lipid is not restricted to one particular cell type, two different cell types were analyzed for the affect of lipid on BTV morphogenesis. The sequestration of VP5 and NS3 to $\mathrm{PI}(4,5) \mathrm{P}_{2}$-enriched endosomal vesicles by Arf6/Q67L expression and a decrease in relative virus titre in the presence of Arf6/Q67L indicated that disruption in the distribution pattern of $\mathrm{PI}(4,5) \mathrm{P}_{2}$ hampered virus particle production. In addition since depletion of $\mathrm{PI}(4,5) \mathrm{P}_{2}$ prior to BTV infection also decreased particle production, the results presented here strongly suggest that $\mathrm{PI}(4,5) \mathrm{P}_{2}$ plays an important role in the BTV life cycle. As neither depleting the level of $\mathrm{PI}(4,5) \mathrm{P}_{2}$ nor altering its distribution disrupted the level of viral proteins, this confirmed 


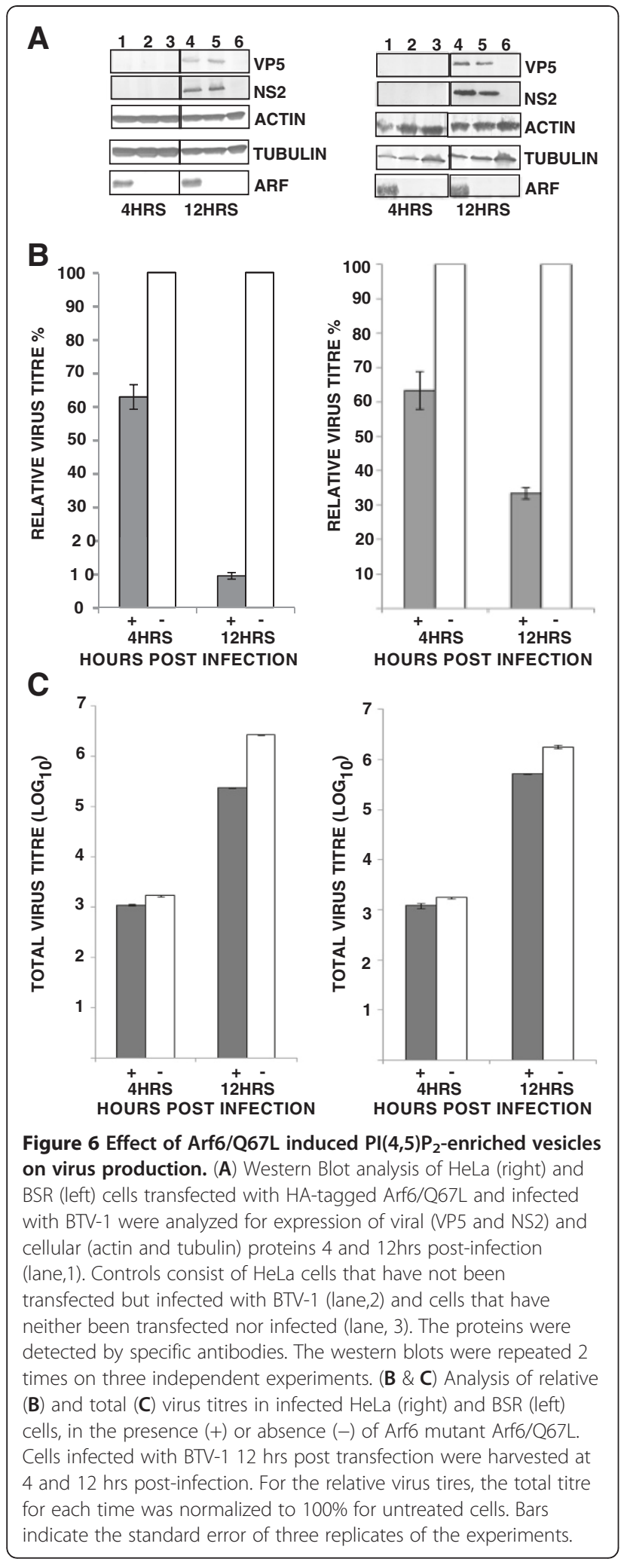

that although $\mathrm{PI}(4,5) \mathrm{P}_{2}$ does play an active role in virus assembly, it does not have any role in viral protein production. Since the early time point (i.e., 4 hrs) showed some virus titres but no viral protein production, this indicated that the titres were due to the presence of the input virus. EM sectioning of BTV infected cells exhibited the attachment of viral particles to the outer surface of vesicle-like structures that were absent in $\mathrm{PI}(4,5) \mathrm{P}_{2}$ depleted cells. Moreover, EM analyses of cells expressing Arf6/Q67L also showed a decrease in virus production. Some studies have reported a co-relation between expression of 5-phosphate IV and apoptosis related decrease in cell viability. However, since our experiments involving confocal microscopy (results not shown) of the BSR and HeLa cells over expressing 5-phosphate IV have not shown any of the gross cellular morphological changes that are usually visible in apoptotic cells, the decrease in virus titer due to reduction of $\mathrm{PI}(4,5) \mathrm{P}_{2}$ can therefore be attributed to the effect of the absence of the lipid in cells and not due to apoptosis induced by over expression of 5-phosphate IV in transfected cells. In addition, previous research has also confirmed that BTV actively induces apoptosis in infected mammalian cells that does not have any negative impact on virus particle production [44].

It is well established that $\mathrm{PI}(4,5) \mathrm{P}_{2}$ plays an important role in the generation and trafficking of intra-cytoplasmic vesicles via the cytoskeletal tracks $[45,46]$. Studies in polarized epithelial cells have revealed that many newly synthesized proteins in the Golgi network, that are destined for the apical surface, are segregated into membrane components rich in sphingolipids and cholesterol [47]. In comparison, proteins destined for the basolateral surface are sorted into vesicles that are predominantly composed of glycerophospholipid. Cells that are not overtly polarized, like the fibroblasts, also deploy these two distinct pathways $[48,49]$. A study comprising of influenza virus hemagglutinin (HA) established that vesicles containing HA were delivered from the Golgi to the cell surface as the infection progressed in the cells. Based on this, it can be hypothesized that disruption of $\mathrm{PI}(4,5) \mathrm{P}_{2}$ in cells either by its depletion or altered distribution hampers the generation of the intracytoplasmic vesicles that might act as hubs for BTV assembly in infected cells. This notion can be substantiated by the fact that NS3 interacts with the two outer capsid proteins of BTV, VP2 and VP5 $[15,24]$ and it also plays an essential role in virus egress $[13,14]$.

The combined data obtained from various experiments in this study provide conclusive evidence of the importance of $\mathrm{PI}(4,5) \mathrm{P}_{2}$ in BTV infection which, to our knowledge, is the first report demonstrating involvement of PI $(4,5) \mathrm{P}_{2}$ in a non-enveloped virus assembly and release. It is also possible that the effect of $\mathrm{PI}(4,5) \mathrm{P}_{2}$ on $\mathrm{BTV}$ 

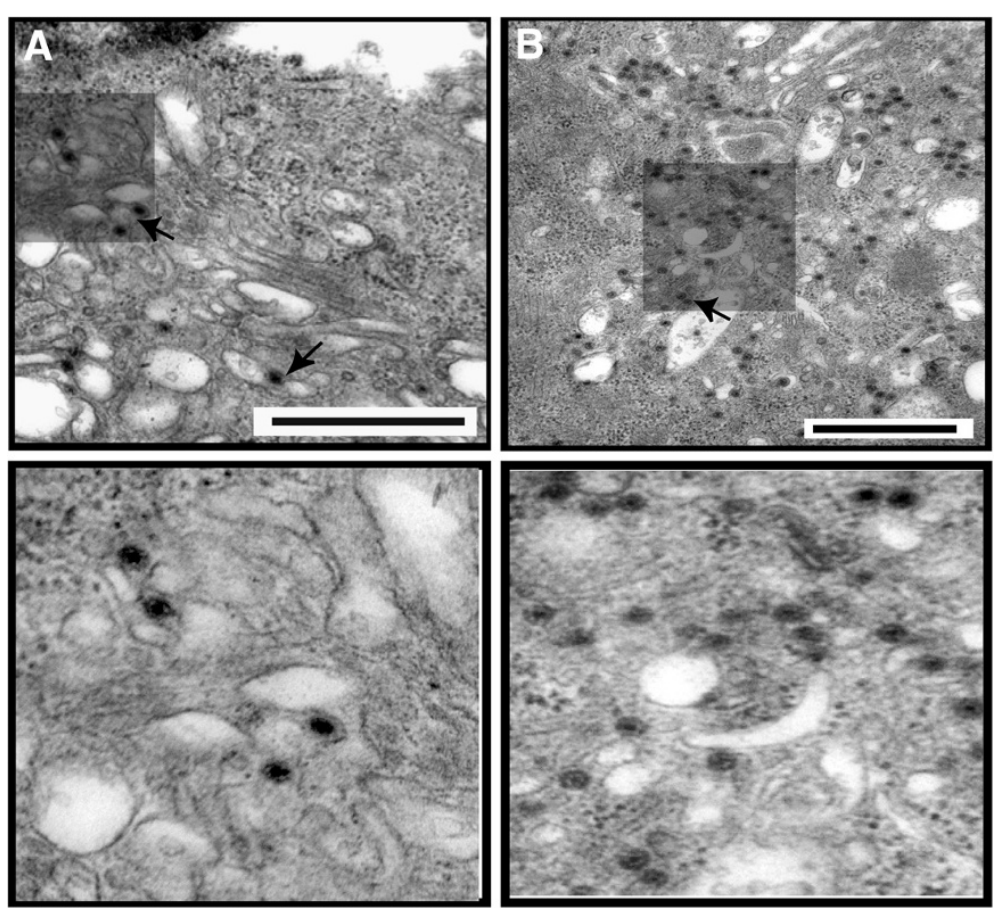

Figure 7 Analysis of sequestration of $\mathrm{PI}(4,5) \mathrm{P}_{2}$ by Arf6/Q67L on BTV particle production by $\mathrm{EM}$. (A). HeLa cells transiently expressing Arf6/ Q67L were infected with BTV-1 and analyzed for virus particle production by EM. (B). Control consists of cells that have not been transiently transfected with plasmid expressing Arf6/Q67L but infected with BTV-1. The presence of virus particles in cell section (upper panel) is indicated by arrows. Lower panels are magnified section. The bars represent magnification of $500 \mathrm{~nm}$.

maturation might also be due to changes in its cellular regulation caused by virus infection or that $\mathrm{PI}(4,5) \mathrm{P}_{2}$ might affect BTV particle production due to its effect on NS3 and VP5 by perturbing the levels of either annexin2 or SNARE proteins, the cellular binding partners of the two viral proteins. Further studies will be necessary to clarify this. Based on our current data it can be hypothesized that common elements may underlie the pathways of virus maturation used by both enveloped and non-enveloped viruses alike.

\section{Conclusion}

The principal findings of this research is that $\operatorname{PI}(4,5) \mathrm{P}_{2}$ influences BTV maturation. In addition this is a unique demonstration of an essential role for negatively charged membrane lipid molecules in the morphogenesis of BTV. It also suggested that the egress pathways of capsid and enveloped viruses may be more closely related than commonly supposed.

\section{Methods}

\section{Cells and viruses}

HeLa (human cervical epithelial) and BSR (a derivative of Baby Hamster Kidney cell) were maintained as described previously [24]. The BSR cells were used to propagate the BTV serotype (BTV-1 SA) and to determine the viral titre by plaque assay. For time course studies of viral infection, HeLa and BSR cell monolayers were washed with FCS-free growth medium and infected with BTV at an MOI of 1. Virus adsorptions were carried out for 30 minutes at $4^{\circ} \mathrm{C}$, followed by incubation at $37^{\circ} \mathrm{C}$ in growth medium supplemented with $2 \%$ FCS for 4 and 12 hrs.

\section{Reagents, buffers and antibodies}

Reagents required for protein interaction and confocal microscopy studies were obtained as described previously [24]. Except for VP2 [50], all the antibodies used against BTV proteins were generated in our laboratory. While various antibodies used in this study against the cellular proteins have been described previously [24], the mouse monoclonal anti-myc (9E10), rabbit polyclonal anti-HA and mouse monoclonal anti $\mathrm{PI}(4,5) \mathrm{P}_{2}$ were obtained from Abcam (Cambridge,UK), Santa Cruz Biotechnology (SantaCruz, USA) and Molecular Probes (USA), respectively.

\section{Plasmids}

Plasmids expressing 5 ptaseIV and $\Delta 1$ mutant lacking the phosphatase signature domain were donated by $\mathrm{P}$. Majerus (Washington University School of Medicine, St. Louis) and Eric Freed (National Cancer Institute, NIH, Frederick, Maryland) respectively. The PHGFP expression plasmids and HA-tagged Arf6/Q67L were donated 
by T. Balla (National Institute of Child Health and $\mathrm{Hu}$ man Development, NIH) and J. Donaldson (National Heart, Lung, and Blood Institute, NIH) respectively.

\section{Transfection}

HeLa cells were seeded in 12 well plates, transfected when 70\% confluent with Lipofectaminine 2000 (Invitrogen) according to the manufacturer's recommendations and incubated for $12 \mathrm{hrs}$ at $37^{\circ} \mathrm{C}$. Subsequently they were infected with the virus, incubated for the various time points and then processed for titration assays, western blot or confocal microscopy assays as described below.

\section{Virus titration}

Cell extracts from BTV-infected and either transfected or treated with tranfecting reagent were collected, freeze thawed three times and virus titres were determined by plaque assays using BSR cells as described previously [51]. The total viral titer was determined and normalized to the titer obtained for infected but untransfected cells. The mean and standard error of the reduction mediated by the inhibitor were calculated (Sigma Plot 2000; Systat Software Inc.).

\section{Western blot}

SDS-PAGE separated proteins were transferred onto a Hybond enhanced chemiluminescence nitrocellulose membrane (GE Healthcare, Uppsala Sweden) and probed with appropriate antibodies. Subsequently, the blots were incubated with alkaline phosphatase conjugated secondary antibodies and developed with BCIPNBT substrate (Sigma-Aldrich). The western blots were repeated 2 times on three independent experiments.

\section{Confocal microscopy}

Mammalian cells were seeded in 24 well plates on 13mm-diameter coverslips, transfected with the expression plasmids and infected with BTV. Subsequently the cells were processed for confocal microscopy as described previously [52]. After analyzing with a Zeiss LSM 510 confocal microscope, the images were obtained using LSM 510 image browser software and processed using Photoshop Elements 2.0 software (Adobe).

\section{Electron microscopy (EM)}

HeLa cells were transfected with the expression plasmids followed by infection with virus and incubated for $12 \mathrm{hrs}$ at $37^{\circ} \mathrm{C}$. The cells were then processed for EM as described previously [14] and examined by a Hitachi H7000 electron microscope. The experiment was repeated twice and 3 different sections per independent experiment were analyzed for the distribution of virus particles. The statistical analysis of the virus particles were undertaken by Sigma Plot 2000 (Systat Software Inc.) and Excel (Microsoft).

\section{Competing interests}

The authors declare that they have no competing interests.

\section{Authors' contributions}

BB conceived, designed and performed the experiments. BB and PR analyzed the data. BB and PR wrote the manuscript. All authors read and approved the final manuscript.

\section{Acknowledgements}

We thank J. Donaldson (National Heart, Lung, and Blood Institute, NIH) and P. Majerus (Washington University School of Medicine, St. Louis), T. Balla (National Institute of Child Health and Human Development, $\mathrm{NIH}$ ) and E. Freed (NIH, Frederick, Maryland) for providing plasmids. We also thank Maria McCrossan (LSHTM) for technical help with electron microscopy experiments and Theresa Ward (LSHTM) for valuable comments in the preparation of the manuscript. This work was funded by NIH, USA.

Received: 11 December 2012 Accepted: 1 March 2013

Published: 5 March 2013

\section{References}

1. Roy P, Noad R: Bluetongue virus assembly and morphogenesis. Curr Top Microbiol Immunol 2006, 309:87-116.

2. Eaton BT, Crameri GS: The site of bluetongue virus attachment to glycophorins from a number of animal erythrocytes. J Gen Virol 1989, 70:3347-3353.

3. Hassan SH, Roy P: Expression and functional characterization of bluetongue virus VP2 protein: Role in cell entry. J Virol 1999, 73:9832-9842.

4. Hassan SH, Wirblich C, Forzan M, Roy P: Expression and functional characterization of bluetongue virus VP5 protein: role in cellular permeabilization. J Virol 2001, 75:8356-8367.

5. Forzan M, Wirblich C, Roy P: A capsid protein of nonenveloped Bluetongue virus exhibits membrane fusion activity. PNAS 2004, 101:2100-2105.

6. Forzan M, Marsh M, Roy P: Bluetongue virus entry into cells. J Virol 2007, 81:4819-4827

7. Zhang X, Boyce M, Bhattacharya B, Zhang X, Scheina S, Roy P, Zhou ZH: Bluetongue virus coat protein VP2 contains a sialic acid-binding domain and VP5 has similarities to enveloped virus fusion proteins. PNAS 2010, 107:6292-6297.

8. Modrof J, Lymperopoulos K, Roy P: Phosphorylation of Bluetongue Virus Nonstructural Protein 2 Is Essential for Formation of Viral Inclusion Bodies. J Virol 2005, 79:10023-10031.

9. Kar AK, Ghosh M, Roy P: Mapping the assembly of Bluetongue virus scaffolding protein VP3. Virology 2004, 324:387-399.

10. Kar AK, Bhattacharya B, Roy P: Bluetongue virus RNA binding protein NS2 is a modulator of viral replication and assembly. BMC Mol Biol 2007, 8:4.

11. Wu X, Chen SY, Iwata H, Compans RW, Roy P: Multiple glycoproteins synthesized by the smallest RNA segment (S10) of bluetongue virus. J Virol 1992, 66:7104-7112.

12. Hyatt $A D$, Zhao $Y$, Roy P: Release of bluetongue virus-like particles from insect cells is mediated by BTV nonstructural protein NS3/NS3A. Virology 1993, 193:592-603.

13. Wirblich C, Bhattacharya B, Roy P: Nonstructural protein 3 of bluetongue virus assists virus release by recruiting ESCRT-I protein Tsg101. J Virol 2006, 80:460-473.

14. Celma CC, Roy P: A viral nonstructural protein regulates bluetongue virus trafficking and release. J Virol 2009, 83:6806-6816.

15. Beaton AR, Rodriguez J, Reddy YK, Roy P: The membrane trafficking protein calpactin forms a complex with bluetongue virus protein NS3 and mediates virus release. Proc Natl Acad Sci USA 2002, 99:13154-13159.

16. Celma CC, Roy P: Interaction of calpactin light chain (S100A10/p11) and a viral NS protein is essential for intracellular trafficking of nonenveloped bluetongue virus. J Virol 2011, 85:4783-4791.

17. Ayala-Sanmartin J, Henry JP, Pradel LA: Cholesterol regulates membrane binding and aggregation by annexin 2 at submicromolar $\mathrm{Ca}(2+)$ concentration. Biochim Biophys Acta 2001, 1510:18-28. 
18. Hayes MJ, Merrifield CJ, Shao D, Ayala-Sanmartin J, Schorey CD, Levine TP, Proust J, Curran J, Bailly M, Moss SE: Annexin A2 binding to phosphatidylinositol 4,5-bisphosphate on endocytic vesicles is regulated by the stress response pathway. J Biol Chem 2004, 279:14157-14164.

19. Rescher U, Ruhe D, Ludwig C, Zobiack N, Gerke V: Annexin 2 is a phosphatidylinositol $(4,5)$-bisphosphate binding protein recruited to actin assembly sites at cellular membranes. J Cell Sci 2004, 117:3473-3480.

20. Chasserot-Golaz S, Vitale N, Umbrecht-Jenck E, Knight D, Gerke V, Bader MF: Annexin 2 promotes the formation of lipid microdomains required for calcium-regulated exocytosis of dense-core vesicles. Mol Biol Cell 2005, 16:1108-1119.

21. Gokhale NA, Abraham A, Digman MA, Gratton E, Cho W: Phosphoinositide specificity of and mechanism of lipid domain formation by annexin A2-p11 heterotetramer. J Biol Chem 2005, 280:42831-42840.

22. Volker G, Creutze CE, Moss SE: Annexins: linking Ca2+ signalling to membrane dynamics. Nat Rev Mol Cell Biol 2005, 6:449-461.

23. Somanath S, Barg S, Marshall C, Silwood CJ, Turner MD: High extracellular glucose inhibits exocytosis through disruption of syntaxin 1A-containing lipid rafts. Biochem Biophys Res Commun 2009, 389:241-246.

24. Bhattacharya B, Roy P: Bluetongue virus outer capsid protein VP5 interacts with membrane lipid rafts via a SNARE domain. J Viro/ 2008, 27:27.

25. Simonsen A, Wurmser A, Emr SD, Stenmark H: The role of phosphoinositides in membrane transport. Curr Opin Cell Biol 2001, 13:485-492

26. Donaldson JG: Multiple roles for Arf6: sorting, structuring, and signaling at the plasma membrane. J Biol Chem 2003, 278:41573-41576.

27. Brown FD, Rozelle AL, Yin HL, Balla T, Donaldson JG: Phosphatidylinositol 4,5-bisphosphate and Arf6-regulated membrane traffic. J Cell Biol 2001, 154:1007-1017.

28. Aikawa $Y$, Martin TF: ARF6 regulates a plasma membrane pool of phosphatidylinositol $(4,5)$ bisphosphate required for regulated exocytosis. J Cell Biol 2003, 162:647-659.

29. Várnai P, Bala T: Visualization of phosphoinositides that bind pleckstrin homology domains: calcium- and agonist-induced dynamic changes and relationship to myo-[3H]inositol-labeled phosphoinositide pools. J Cell Biol 1998, 143:501-510

30. Kisseleva MV, Wilson MP, Majerus PW: The isolation and characterization of a CDNA encoding phospholipid-specific inositol polyphosphate 5-phosphatase. J Biol Chem 2000, 275:20110-20116.

31. Ono A, Ablan SD, Lockett SJ, Nagashima K, Freed EO: Phosphatidylinositol $(4,5)$ bisphosphate regulates HIV-1 Gag targeting to the plasma membrane. PNAS 2004, 101:14889-14894.

32. Kar AK, Iwatani N, Roy P: Assembly and intracellular localization of the bluetongue virus core protein VP3. J Virol 2005, 79:11487-11495.

33. Kisseleva MV, Cao L, Majerus PW: Phosphoinositide-specific inositol polyphosphate 5-phosphatase IV inhibits Akt/Protein Kinase B phosphorylation and leads to apoptotic cell death. J Biol Chem 2002, 277:6266-6272.

34. Honda A, Nogami M, Yokozeki T, Yamazaki M, Nakamura $H$, Watanabe $H_{\text {, }}$ Kawamoto K, Nakayama K, Morris AJ, Frohman MA, Kanaho Y: Phosphatidylinositol 4-phosphate 5-kinase alpha is a downstream effector of the small G protein ARF6 in membrane ruffle formation. Cell Biol 1999, 99:521-532.

35. Holz RW, Hlubek M, Sorensen SD, Fisher SK, Balla T, Ozaki S, Prestwich GD, Stuenkel EL, Bittner MA: A pleckstrin homology domain specific for phosphatidylinositol 4,5-bisphosphate (Ptdlns-4,5-P2) and fused to green fluorescent protein identifies plasma membrane Ptdlns-4,5-P2 as being important in exocytosis. J Biol Chem 2000, 275:17878-17885.

36. Bai J, Tucker WC, Chapman ER: PIP2 increases the speed of response of synaptotagmin and steers its membrane-penetration activity toward the plasma membrane. Nat Struct Mol Biol 2004, 11:36-44.

37. Raposo G, Moore M, Innes D, Leijendekker R, Leigh-Brown A, Benaroch $P$ Geuze H: Human macrophages accumulate HIV-1 particles in MHC II compartments. Traffic 2002, 3:718-729.

38. Pelchen-Matthews A, Kramer B, Marsh M: Infectious HIV-1 assembles in late endosomes in primary macrophages. J Cell Biol 2003, 162:443-455

39. Nydegger S, Foti M, Derdowski A, Spearman $P$, Thali M: HIV-1 egress is gated through late endosomal membranes. Traffic 2003, 4:902-910.

40. Sherer NM, Lehmann MJ, Jimenez-Soto LF, Ingmundson A, Horner SM, Cicchetti G, Allen PG, Pypaert M, Cunningham JM, Mothes W: Visualization of retroviral replication in living cells reveals budding into multivesicular bodies. Traffic 2003, 4:785-801.

41. Zhou W, Parent $\sqcup$, Wills JW, Resh MD: Identification of a membranebinding domain within the amino-terminal region of human immunodeficiency virus type $1 \mathrm{Gag}$ protein which interacts with acidic phospholipids. J Virol 1994, 68:2556-2569.

42. Chukkapalli V, Hogue IB, Boyko V, Hu WS, Ono A: Interaction between the human immunodeficiency virus type 1 gag matrix domain and phosphatidylinositol-(4,5)-bisphosphate is essential for efficient gag membrane binding. J Virol 2008, 82:2405-2417.

43. Hamard-Peron E, Juillard F, Saad JS, Roy C, Roingeard P, Summers MF, Darlix \lrcorner , Picart C, Muriaux D: Targeting of murine leukemia virus gag to the plasma membrane is mediated by $\mathrm{PI}(4,5) \mathrm{P} 2 / \mathrm{PS}$ and a polybasic region in the matrix. J Virol 2010, 84:503-515.

44. Stewart ME, Roy P: Role of cellular caspases, nuclear factor-kappa B and interferon regulatory factors in Bluetongue virus infection and cell fate. Virol J 2010, 7:362

45. Kanzaki M, Furukawa M, Raab W, Pessin JE: Phosphatidylinositol 4,5bisphosphate regulates adipocyte actin dynamics and GLUT4 vesicle recycling. J Biol Chem 2004, 279:30622-30633.

46. Cremona O, Di Paolo G, Wenk MR, Lüthi A, Kim WT, Takei K, Daniell L, Nemoto Y, Shears SB, Flavell RA, McCormick DA, De Camilli P: Essential role of phosphoinositide metabolism in synaptic vesicle recycling. Cell 1999, 99:179-188.

47. Harder TS, Simons K: Caveolae, DIGs and the dynamics of sphingolipidcholesterol microdomains. Curr Opin Cell Biol 1997, 9:534-542.

48. Yoshimori T, Keller P, Roth MG, Simons K: Different biosynthetic transport routes to the plasma membrane in BHK and CHO cells. J Cell Biol 1996, 133:247-256.

49. Harder $T$, Scheiffele $P$, Verkade $P$, Simons K: Lipid domain structure of the plasma membrane revealed by patching of membrane components. J Cell Biol 1998, 141:929-942.

50. DeMaula CD, Heidner HW, Rossitto PV, Pierce CM, MacLachlan NJ: Neutralization determinants of United States bluetongue virus serotype 10. Virology 1993, 195:292-296.

51. Bhattacharya $B$, Roy $P$ : Role of lipids on entry and exit of bluetongue virus, a complex non-enveloped virus. Viruses 2010, 2:1218-1235.

52. Bhattacharya B, Noad RJ, Roy P: Interaction between Bluetongue virus outer capsid protein VP2 and vimentin is necessary for virus egress. Virol J 2007, 4:7.

\section{doi:10.1186/1743-422X-10-73}

Cite this article as: Bhattacharya and Roy: Cellular phosphoinositides and the maturation of bluetongue virus, a non-enveloped capsid virus. Virology Journal 2013 10:73.

\section{Submit your next manuscript to BioMed Central and take full advantage of:}

- Convenient online submission

- Thorough peer review

- No space constraints or color figure charges

- Immediate publication on acceptance

- Inclusion in PubMed, CAS, Scopus and Google Scholar

- Research which is freely available for redistribution 